\title{
Assessment of Quality of Care Provided to Hypertensive Patients in Primary Health Care Units in Ismailia City
}

\author{
Nadeen S. Ahmed, Hanan A. Abd El-Rahman, Nahed A. El-Dahshan \\ Family Medicine Department, Faculty of Medicine, Suez Canal University
}

Received: February, 2018 Accepted: May, 2018

\begin{abstract}
Background: Several studies examined the link between care processes and controlled hypertension (HTN). However, these studies may not serve as the best preface to the current state of quality of care in primary health care (PHC). Previous analyses often comprised regional rather than national data, probably restrict the generalizability of the results. Furthermore, no such researches were accomplished in Egypt. Objective: to assess the quality of care provided to hypertensive patients at PHC units in Ismailia city. Method: Seventy-two hypertensive patients regularly follow-up at PHC for $>6$ months were recruited into the study. Data was collected from (1) Care Performance measures, (2) Quality of Care indicators, (3) Patients' Satisfaction (patient's perspective about quality of care) by Arabic version of Client Perception of Coordination Questionnaire (CPCQ), and (4) Patients' characteristics. Results: The frequency of inadequate care performance was $56.9 \%$. Only $5.6 \%$ of our patients were under health insurance coverage. The most common deficient indicator for quality of care was performing lifestyle modification (5.6\%). Approximately $60 \%$ of the patients had uncontrolled HTN and $59.7 \%$ of the cases had positive perception about the care. The most common problems facing the patients were waiting too long till receiving the services $(83.3 \%$ ) and $23.6 \%$ of the studied patients didn't have any caregiver. Significant factors affecting care performance were health insurance coverage, degree of caregiver involvement and quality of care adequacy. Conclusion: Quality of care provided to hypertensive patients at the PHC in Ismailia City was inadequate.
\end{abstract}

Keywords: Care performance, patients'satisfaction, client perception.

Corresponding author: Nadeen S. Ahmed, Email: nadeen_sabry@hotmail.com

\section{Introduction}

Globally cardiovascular disease accounts for approximately 17 million deaths a year, nearly one third of the total. ${ }^{1}$ The 2017 American College of Cardiology/American Heart Association (ACC/AHA) Guideline for the Prevention, Detection, Evaluation, and Management of High Blood Pressure in Adults lowered the threshold for the definition of hypertension. The 2017 ACC/AHA guideline describes the condition as a systolic blood pressure (SBP) greater than or equal to $130 \mathrm{~mm}$ $\mathrm{Hg}$ or a diastolic blood pressure (DBP) greater than or equal to $80 \mathrm{~mm} \mathrm{Hg}^{2}$ Application of this revised definition may reclassify a significant proportion of people as hypertensive who were previously categorized as prehypertensive, or people with high normal blood pressure. The benefit of this would be to potentially catch individuals earlier in disease progression and reduce cardiovascular morbidity and mortality. A number of studies to date have estimated the adjusted prevalence of hypertension in some countries according to the new guideline. ${ }^{3,4}$ Muntner et al 
examined the effects of the new definition by assessing the hypertension prevalence in the United States and found an absolute increase of $14.7 \%$ among people aged 20 years or older. Additionally, Khera et al estimated the relative increase of prevalence among adults aged 45 to 75 years in the United States and China and found an overall relative increase of $45.1 \%$ and $26.8 \%$ in these 2 countries, respectively. 3,4

The Chronic Care Model (CCM) is a well-established organizational framework for chronic care management and practice improvement. ${ }^{5,6}$ There is a significant evidence base to support the effectiveness of the model. ${ }^{6,7}$ In addition, the comprehensive, multisystem approach of the CCM makes it ideal for working with the vulnerable populations often seen in nurse practitioners (NPs) practices. The CCM consists of 6 distinct concepts identified as modifiable components of healthcare delivery: organizational support, clinical information systems, delivery system design, decision support, selfmanagement support, and community resources. $^{8,9}$ It has been shown that lowering systolic BP (SBP) to $150 \mathrm{~mm}$ $\mathrm{Hg}$ decreases the incidence of all types of strokes. ${ }^{10}$ Although treatment reduces mortality, morbidity and costs, nearly half of all people with HTN go untreated and only $23 \%$ control their BP to the recommended level. ${ }^{11}$

In previous studies, general measures of hypertensive quality were examined (including treatment, diagnosis, and follow-up indicators) and found that these care processes were associated with BP control in young women participating in a single health plan. ${ }^{12}$ Studies of PHC patients conducted 10 years ago suggested that only about $50 \%$ of patients with HTN, and $40-60 \%$ of patients with diabetes, received appropriate care. ${ }^{13,14}$ While informative, these studies may not serve as the best preface to the current state of clinical quality in PHC. Previous analyses often included regional rather than national data, possibly limiting the generalizability of the findings.

Hypertension is a silent, invisible killer that rarely causes symptoms. Increasing public awareness is key, as is access to early detection. Raised blood pressure is a serious warning sign that significant lifestyle changes are urgently needed. People need to know why raised blood pressure is dangerous, and how to take steps to control. To raise this kind of awareness, countries need systems and services in place to promote universal health coverage and support healthy lifestyles: eating a balanced diet, reducing salt intake, avoiding harmful use of alcohol, getting regular exercise and shunning tobacco. Access to good quality medicines, which are effective and inexpensive, is also vital, particularly at the primary care level. As with other non-communicable diseases, awareness aids early detection while self-care helps ensure regular intake of medication, healthy behaviours and better control of the condition.

HTN is known to be a strong risk factor for stroke and coronary heart diseases. In spite of all these facts, a high percentage of victims are unaware that they have HTN, and those who are known to have HTN are not adequately controlled In order to manage this common health problem adequately this study was to assess the quality of HTN care at It has been shown that lowering systolic BP (SBP) to $150 \mathrm{~mm} \mathrm{Hg}$ decreases the incidence of all types of strokes. ${ }^{10}$ Although treatment reduces mortality, morbidity and costs, nearly half of all people with HTN go untreated and only $23 \%$ control their BP to the recommended level. ${ }^{11}$

In previous studies, general measures of hypertensive quality were examined (including treatment, diagnosis, and follow-up indicators) and found that these care processes were associated with 
BP control in young women participating in a single health plan. ${ }^{12}$ Studies of PHC patients conducted 10 years ago suggested that only about $50 \%$ of patients with HTN, and $40-60 \%$ of patients with diabetes, received appropriate care. ${ }^{13,14}$ While informative, these studies may not serve as the best preface to the current state of clinical quality in PHC. Previous analyses often included regional rather than national data, possibly limiting the generalizability of the finding no such studies were performed here in Egypt. To address this gap in the PHC literature, this study aims to provide analysis of clinical quality of care performance offered to hypertensive patient across the primary health centers in Ismailia city.

The general objective is to improve the quality of care provided to hypertensive patients at PHC, in Ismailia city. Specific objectives: To assess the quality of care provided to hypertensive patients at the PHC in Ismailia City.

To define the relationship between the PHC quality of care for hypertensive patient and patient satisfaction.

\section{Method}

This cross-sectional study is designed to assess the quality of care provided to hypertensive at the urban PHC in Ismailia City, Egypt. Four PHCUs were included; Elshikh Zayed, Elsalam, Elshohdaa and Elsabah banat. Seventy two hypertensive patients from these four PHCUs (18 patients from every unit) were selected to assess the quality of the received care

The sample size was calculated according to the following equation:

$\mathrm{n}=2\left(\mathrm{Z}_{\alpha}+\mathrm{Z}_{\beta}\right)^{2} \times \mathrm{p} \mathrm{q} /\left(\mathrm{p}^{1}-\mathrm{p}^{2}\right)^{223}$

$(1.96 / 0.1) 2 \times 0.263 \times 0.637=65$ patients

Where $\mathrm{n}=$ number of patients, $\mathrm{Z} / \mathrm{D}=$ the value of standard normal distribution for type I error probability for sided test and equals $1.96 / 0.1 . \mathrm{q}=1-\mathrm{p}$.

Medical record samples:

The same sample size will be taken from
Classification of Blood Pressure Levels ${ }^{15}$

\begin{tabular}{lcc}
\multicolumn{1}{c}{ Category } & $\begin{array}{c}\text { SBP } \\
(\mathbf{m m H g})\end{array}$ & $\begin{array}{c}\text { DBP } \\
(\mathbf{m m H g})\end{array}$ \\
\hline Normal BP & $<120$ & $<80$ \\
Pre-HTN & $120-139$ & $80-89$ \\
Stage 1 HTN & $140-159$ & $90-99$ \\
Stage 2 HTN & $\geq 160$ & $\geq 100$ \\
HTN= Hypertension, SBP $=$ systolic blood \\
pressure, DBP=diastolic blood pressure.
\end{tabular}

medical records. The following are the inclusion criteria: Hypertensive patients with $\geq$ BP $140 / 90$ or take treatment for HTN of both sex, patients aged 18 years or more, patients with BP $140 / 90$ or more or who take treatment for HTN, patients not having any other diseases or taking drugs for any other diseases documented at family records of patients, mentally competent patients, regular follow up at PHC, patient receiving care from primary health care center for more than 6 months.

Exclusion Criteria included pregnant patients, patients having co-morbid diseases.

Tools of the study: Five Care Performance measures (processes of care and outcome measures $)^{15}$ included (1) HTN screening, defined as the percentage of patients aged 18 years or older who received routine BP screening conducted in a clinician's office using an arm cuff and a calibrated sphygmomanometer. (2) Access to hypertensive care, defined as the percentage of patients who began care in the first year of diagnosis. (3) Prescription of management plan, defined as the percentage of patients who were counseled and encouraged to make therapeutic lifestyle changes and prescribed necessary antihypertensive drug therapy. (4) Follow-up, defined as the percentage of patients who were diagnosed with HTN and regularly follow-up in a scheduled visit. Patients should return for follow-up and adjustment of medications at monthly intervals or less until the BP goal reached. After BP is at goal and stable, follow-up visits can usually be at 3- to 6- 
month intervals, or more often if necessary. (5) HTN control, defined as the percentage of adults 18-85 years diagnosed HTN whose last BP measurement was less than 140/90.

Quality of Care indicators (assessment of quality of care provided to hypertensive patients at PHC for the last

\section{Screening}

1.SBP and DBP should be measured in adult women otherwise presenting for care at least once each year

\section{Diagnosis}

2.Patients with a new diagnosis of stage 1-2 HTN should have at least 3 measurement on different days with a mean SBP of $>140 \mathrm{~mm} \mathrm{Hg}$ and/or a mean DBP of $>90 \mathrm{~mm} \mathrm{Hg}$.

3. Initial history and physical examination of patients with HTN should document assessment of at least 2 items from each of the following groups(:

3a. History: Family or personal history of premature CVD, diabetes, or hyperlipidemia.

3b.Medication or substance use: Personal history of tobacco abuse, alcohol abuse, or medications that may cause HTN.

3c.Physical examination: Examinations of the fundi, heart sounds, abdomen for bruits, peripheral arterial pulses, and neurologic system.

4.Stage 1+ hypertensive women taking drugs that may cause HTN should have the drug discontinued (at least temporarily) before pharmacotherapy is initiated (e.g. oral contraceptives, nasal decongestants, appetite suppressants, monoamine oxidase inhibitors and tricyclic antidepressants)

5. Initial laboratory tests should include the following:
5a. Urine analysis
5b. Glucose
5c.Potassium
5d. Creatinine
5e.Cholesterol
5f.Triglyceride

6. Patients with average SBP of $>140 \mathrm{~mm} \mathrm{Hg}$ or DBP of $>90 \mathrm{~mm} \mathrm{Hg}$ as determined on at least 3 separate visits, should have a diagnosis of HTN documented in their record.

\section{Treatment}

7. First- Line treatment for HTN is lifestyle modification. The medical record should indicate counseling for at least 1 of the following interventions before pharmacotherapy.

- Weight reduction

- Increased physical activity

- Low-sodium diet

- Alcohol intake reduction

8. stage 1-2+ hypertensive patients whose blood pressure remains stage $1-2+$ after 6 months of lifestyle medication should receive pharmacotherapy.

\section{Follow-up}

9.Hypertensive patients should visit the provider at least once each year.

10. Hypertensive patients with persistent elevations of SBP of $>160 \mathrm{~mm} \mathrm{Hg}$ or DBP of $>90 \mathrm{~mm} \mathrm{Hg}$ should have 1 of the following interventions recorded in the medical records.

- Change in dose or regimen of antihypertensive agents.

- Repeated education regarding lifestyle modifications.

$H T N=$ Hypertension, $S B P=$ systolic blood pressure, $D B P=$ diastolic blood pressure, $C V D=$ cardiovascular disease

Patients' Satisfaction (patients' perspective about quality of care) Patients' Satisfaction was assessed by CPCQ translated into Arabic by College of Culture Suez Canal University. The questionnaire contained 25 items, available responses for each item range

\begin{abstract}
from "Never" with a value of "1", "Rarely" with a value of "2", "Sometimes" with a value of " 3 ", "Mostly" with a value of " 4 " and "Always" with a value of " 5 ". 17

Patients' characteristics were determined (e.g. age, gender, marital status,
\end{abstract}


occupation, educational level, smoking and health insurance coverage).

Pilot Study: The questionnaire was pretested on ten patients before the beginning of data collection test the relevance of the questionnaire to the objectives of the study, determine if the questions asked were understood by the respondents or not, to perform any modification needed, to determine the needed time to complete questionnaire. These results were not going to be included in the study.

Data Management and Statistical Analysis

Data collected was coded, entered and analyzed using Microsoft Excel software. Statistical Package for Social Science 16 (SPSS 16) for Windows were used for data analysis. The independent data of the study were analyzed. Analysis of the clinical profile, sociodemographic and other variables. Firstly, the relation between the dependent and independent variables were studied using the Chisquare test and the t-test. Second, the significant variables will be subjected to multiple logistic regression analysis. Values of a $p<0.05$ were considered statistically significant. We considered various factors in selecting the covariates to be included in our analyses. First, we considered all the variables that are statistically related to the various clinical performance measures in bivariate analyses. We identified variables which found to have a significant impact on clinical quality and outcomes. We then considered problems relating to multico linearity between variables and remove certain variables which are closely related to address this issue. accounting for key patient and measure institutional characteristics, which would and which would be of particular interest and policy relevance to primary health care centers. Considering all of these factors, we were opt for a general model of clinical quality accounting for key patient and institutional characteristics, which would be relevant regardless of the specific measure and which would be of particular interest and policy relevance to primary health care centers.

Table 1: Sociodemographic characteristics of the studied patients $(n=72)$ :

\begin{tabular}{|c|c|}
\hline Variables & $\begin{array}{c}\text { Studied } \\
\text { patients } \\
(\mathrm{n}=72)\end{array}$ \\
\hline \multicolumn{2}{|l|}{ Age (years), $n(\%)$} \\
\hline $30-$ & $7(9.7)$ \\
\hline $45-$ & $43(59.7)$ \\
\hline $60+$ & $22(30.6)$ \\
\hline Mean \pm SD & $53.9 \pm 8.3$ \\
\hline Range & $31-68$ \\
\hline \multicolumn{2}{|l|}{ Gender, $n(\%)$} \\
\hline Male & $8(11.1)$ \\
\hline Female & $64(88.9)$ \\
\hline \multicolumn{2}{|l|}{ Marital status, $n(\%)$} \\
\hline Unmarried & $17(23.6)$ \\
\hline Married & $55(76.4)$ \\
\hline \multicolumn{2}{|l|}{ Occupation, $n(\%)$} \\
\hline House Wife & $60(83.3)$ \\
\hline Semi-professional working & $7(9.7)$ \\
\hline Business working & $3(4.2)$ \\
\hline Manual working & $2(2.8)$ \\
\hline \multicolumn{2}{|l|}{ Educational level, $n$ (\%) } \\
\hline Illiterate & $24(33.3)$ \\
\hline Read \& write & $16(22.2)$ \\
\hline Primary/ secondary & $31(43.1)$ \\
\hline High Education & $1(1.4)$ \\
\hline \multicolumn{2}{|l|}{ Smoking, $n(\%)$} \\
\hline Non-smokers & $70(97.2)$ \\
\hline Smokers & $2(2.8)$ \\
\hline \multicolumn{2}{|c|}{$\begin{array}{l}\text { Health insurance coverage, } n \\
(\%)\end{array}$} \\
\hline Non-insured & $68(94.4)$ \\
\hline Insured & $4(5.6)$ \\
\hline $\begin{array}{l}\text { SD=standard deviation, } \\
\text { and housewives, } \\
\text { working }=\text { clerk, social wo wo } \\
\text { teachers and nurses, business } \\
\text { sellers and sales managers. }\end{array}$ & $\begin{array}{l}\text { ing }=\text { retired } \\
\text { professional } \\
\text { librarians, } \\
g=\text { traders }\end{array}$ \\
\hline
\end{tabular}

\section{Ethical Considerations}

An informed consent was obtained from all the participants before taking any data or doing any investigations. The consent is containing explanation of the study 
aim in a simple manner to be understood by lay people. No harmful maneuvers will be performed or used. All data were considered confidential and will not going to be used outside this study without patient's approval. All data were used in this research only. Researcher phone number and all possible communicating methods were identified to the participants to return at any time for any explanation. All participants were announced by the result of the study. Participants had the right to withdraw from the study at any time without giving any reason. Any professional help that was needed by the study subjects was provided or arranged by the investigator. Signature fingerprints of the patients were taken.

\section{Results}

This study was conducted to assess the quality of care provided to hypertensive patients at the PHC in Ismailia City, Egypt. Four PHCUs were included; Elshikh Zayed, Elsalam, Elshohdaa and Elsabah banat. Sevetny two hypertensive patients from these four PHCUs (18 patients from every unit) were selected to assess the quality of the received care. All the studied PHCUs were large units which has been working for more than 10 years. The four centers were using records as data reporting method. Table (7) showed that caregivers wereinvolved in the decision making of the received care $(83.2 \%)$ and caregivers were satisfied with the received care $(90.3 \%)$.

The most common deficient indicators for assessment of quality of care provided to hypertensive patients were performing lifestyle modification $(5.6 \%)$

Table (9) shows the multivariate regression analysis model of factors affecting care performance among the studied patients. Significant factors were absence of health insurance, presence of stage I HTN, degree of caregiver involvement, and adequate quality of care.

Table (2) Blood pressure (BP) measurement of the studied patients $(n=72)$

\begin{tabular}{lc}
\multicolumn{1}{c}{ Variables } & $\begin{array}{c}\text { Studied patients } \\
(\mathbf{n = 7 2}) \mathbf{N}(\boldsymbol{\%})\end{array}$ \\
\hline Stages of HTN & \\
Stage I HTN & $54(75.0)$ \\
Stage II HTN & $18(25.0)$ \\
\hline Systolic BP & \\
$<140 \mathrm{mmHg}$ & $41(56.9)$ \\
$\geq 140 \mathrm{mmHg}$ & $31(43.1)$ \\
Mean \pm SD & $136.67 \pm 14.41$ \\
Range & $110-180$ \\
\hline Diastolic BP & $35(48.6)$ \\
$<90 \mathrm{mmHg}$ & $37(51.4)$ \\
$\geq 90 \mathrm{mmHg}$ & $86.11 \pm 9.39$ \\
Mean \pm SD & $70-110$ \\
Range & \\
\hline HTN $=$ Hypertension. &
\end{tabular}

Table (3) Five care performance measures among the studied patients $(n=72)$

\begin{tabular}{|c|c|}
\hline \multirow[t]{2}{*}{ Variables } & $\begin{array}{c}\text { Studied } \\
\text { patients } \\
(n=72)\end{array}$ \\
\hline & No. $(\%)$ \\
\hline \multicolumn{2}{|l|}{$\begin{array}{l}\text { Five care performance } \\
\text { measures }\end{array}$} \\
\hline $\begin{array}{l}\text { Number of patients who received } \\
\text { routine BP screening }\end{array}$ & $72(100.0)$ \\
\hline $\begin{array}{l}\text { Number of patients who began } \\
\text { care in the } 1^{\text {st }} \text { year of diagnosis }\end{array}$ & $70(97.2)$ \\
\hline $\begin{array}{l}\text { Number of patients who initiated } \\
\text { therapeutic lifestyle changes }\end{array}$ & $4(5.6)$ \\
\hline $\begin{array}{l}\text { Number of patients who regularly } \\
\text { follow-up (every 3-6 months) }\end{array}$ & $30(41.7)$ \\
\hline $\begin{array}{l}\text { Number of patients who had the } \\
\text { last BP measurement }<140 / 90\end{array}$ & $29(40.3)$ \\
\hline \multicolumn{2}{|l|}{$\begin{array}{l}\text { Total score of care } \\
\text { performance }\end{array}$} \\
\hline Inadequate & $41(56.9)$ \\
\hline Adequate & $31(43.1)$ \\
\hline Mean \pm SD & $2.92 \pm 1.03$ \\
\hline Range & $2-5$ \\
\hline
\end{tabular}

\section{Discussion}

The present study shows that more than one-third of the studied patients $(34.7 \%)$ had a family history of HTN. Which is in agreement with study done at PHC 
Centers at Abha, Saudi Arabia, 25\% of their patients had positive family history. ${ }^{18}$

Our study revealed that the mean age of the studied patients was $53.9 \pm 8.3$ years.

The demographic risk factors including age was evaluated in several studies. Individals aged between 45 to 62 years had three-folds more common of hypertenion. ${ }^{19}$ In addition, Sheppard et al. ${ }^{20}$ mentioned that stage 1 HTN was more common in age group 40-54 years versus age group 55-74 years. In 2015, Gebreselassie and Padyab ${ }^{21}$ reported that the most frequent age group of stage I hypertensive individuals was between 50 to 59 years in Ghana $(28.3 \%)$ and between 70 to 74 years in South Africa $(33.1 \%)$.

The present study also reported that the frequency of female patients was higher than male patients $(88.9 \%$ versus $11.1 \%$, respectively). This female-to-male difference may be attributed to the higher attendance rate of female patients to PHCUs in comparison to male patients at the morning (day) session. The reasons for this increased attendance are generally due to the higher involvement of women in the healthcare provided to their children and other sick relatives. ${ }^{22}$

This is in agreement with several Arab studies found that more than $50 \%$ of the hypertensive patients were females. ${ }^{23}$ Ibrahim et al. ${ }^{26}$, Tazi et al. ${ }^{24}$, Bener et al. ${ }^{25}$, Al-Nozha et al. ${ }^{26}$ and Temmar et al. ${ }^{27}$ studies found that HTN prevalence was greater in females.

Our research indicated that the prevalence of stage I HTN was $75 \%$ and stage II was $25 \%$. The prevalence of HTN varied widely in the Arab countries. The prevalence of stage II HTN ranged from $16.3 \%$ in Jordan ${ }^{28}$ to $35.3-44 \%$ in Algeria. $^{29}$ Meanwhile, stage II HTN prevalence ranged from $25.2 \%$ (Oman) ${ }^{30}$ to $39.6 \%$ (Morocco). ${ }^{24}$
The literature review revealed a higher prevalence of HTN in Arab countries (29.5\%) compared to the USA $(28 \%)^{31}$ and sub-Saharan Africa $(27.6 \%){ }^{32}$ However, the prevalence of HTN in Arab countries was lower compared to European countries $(44.2 \%) .33,34$

The difference in methodology of BP measurement between studies might also have influenced the prevalence of HTN and explain the variability. The main differences between these studies were the use of different equipment (i.e. sphygmomanometer versus electronic $\mathrm{BP}$ monitor), the number of $\mathrm{BP}$ measurements, and the method used to estimate the mean BP measurements (i.e. last two measurements versus all measurements). ${ }^{35}$

Our study reported that all patients received routine $\mathrm{BP}$ screening. It was in disagreement with the study done by Asch et al. ${ }^{36}$ in which $84.2 \%$ of their patients received routine BP screening the difference may be due to different sample size between two studies.

Regarding routine BP screening, there is universal agreement among major national primary care organizations, including The JNC on Prevention, Detection and Treatment of HTN, the United States Preventative Service Task Force, the American Academy of Family Physicians, and the American College of Physicians on the utility of screening for HTN and the optimal interval for screening adults for HTN is not known. ${ }^{35}$

From our total studied patients $(n=72)$, the patients who started antihypertensive management during the first year were $97.2 \%$. In similar manner, Ibrahim ${ }^{37}$ stated that around $80 \%$ of the total hypertensive patients began their treatment within the first year of diagnosis. He also declared that because of high prevalence of HTN in Egypt, the 
Table (4) Patient perception about the received care according to Client Perception of Coordination Questionnaire (CPCQ) $(n=72)$

\begin{tabular}{|c|c|c|c|c|c|c|}
\hline \multirow{2}{*}{ Variables } & \multicolumn{6}{|c|}{ Patients' response (\%) } \\
\hline & Never & Rarely & Sometimes & Mostly & Always & NA \\
\hline Receiving the needed services & $0(0.0)$ & $3(4.2)$ & $10(13.9)$ & $35(48.6)$ & $24(33.3)$ & $0(0.0)$ \\
\hline $\begin{array}{l}\text { Waiting too long till receiving the } \\
\text { services }\end{array}$ & $0(0.0)$ & $12(16.7)$ & $26(36.1)$ & $15(20.8)$ & $19(26.4)$ & $0(0.0)$ \\
\hline $\begin{array}{l}\text { Being difficult to get transport to } \\
\text { services }\end{array}$ & $35(48.6)$ & $13(18.1)$ & $4(5.6)$ & $2(2.8)$ & $1(1.4)$ & $17(23.6)$ \\
\hline $\begin{array}{l}\text { Receiving the needed medicine in the } \\
\text { past } 3 \text { months }\end{array}$ & $0(0.0)$ & $2(2.8)$ & $9(12.5)$ & $47(65.3)$ & $14(19.4)$ & $0(0.0)$ \\
\hline $\begin{array}{l}\text { Unnecessarily tests or assessments by } \\
\text { providers }\end{array}$ & $12(16.7)$ & $19(26.4)$ & $13(18.1)$ & $9(12.5)$ & $1(1.4)$ & $18(25)$ \\
\hline $\begin{array}{l}\text { Ttests or assessments being discussed } \\
\text { with patients }\end{array}$ & $0(0.0)$ & $7(9.7)$ & $12(16.7)$ & $19(26.4)$ & $32(44.4)$ & $2(2.8)$ \\
\hline Receiving services as coordinated & $0(0.0)$ & $4(5.6)$ & $22(30.6)$ & $35(48.6)$ & $11(15.3)$ & $0(0.0)$ \\
\hline $\begin{array}{l}\text { Feeling happy with the quality of } \\
\text { received care }\end{array}$ & $0(0.0)$ & $2(2.8)$ & $26(36.1)$ & $15(20.8)$ & $29(40.3)$ & $0(0.0)$ \\
\hline $\begin{array}{l}\text { Being confused about the roles of } \\
\text { different service providers }\end{array}$ & $12(16.7)$ & $29(40.3)$ & $19(26.4)$ & $5(6.9)$ & $0(0.0)$ & $7(9.7)$ \\
\hline $\begin{array}{l}\text { Providers' response to patients' needs } \\
\text { changes in past } 3 \text { months }\end{array}$ & $0(0.0)$ & $5(6.9)$ & $16(22.2)$ & $21(29.2)$ & $16(22.2)$ & $14(19.4)$ \\
\hline $\begin{array}{l}\text { Getting conflicting advice from service } \\
\text { providers }\end{array}$ & $11(15.3)$ & $28(38.9)$ & $10(13.9)$ & $5(6.9)$ & $0(0.0)$ & $18(25)$ \\
\hline Complaining about care & $20(27.8)$ & $22(30.6)$ & $25(34.7)$ & $2(2.8)$ & $1(1.4)$ & $2(2.8)$ \\
\hline Understanding own condition & $0(0.0)$ & $1(1.4)$ & $14(19.4)$ & $31(43.1)$ & $26(36.1)$ & $0(0.0)$ \\
\hline Being able to cope with life & $0(0.0)$ & $1(1.4)$ & $21(29.2)$ & $20(27.8)$ & $30(41.7)$ & $0(0.0)$ \\
\hline $\begin{array}{ll}\text { Total } & \text { Positive }(>60 \%) \\
\text { perception } & \text { Negative }(<60 \%) \\
\end{array}$ & & & $\begin{array}{l}43(59 \\
29(40 \\
\end{array}$ & $\begin{array}{l}7 \%) \\
3 \%) \\
\end{array}$ & & \\
\hline $\begin{array}{ll}\text { Overall } & \text { Satisfied } \\
\text { satisfaction } & \text { Neutral } \\
\text { level } & \text { Dissatisfied } \\
\end{array}$ & & & $\begin{array}{l}47(65 \\
14(19 \\
11(15\end{array}$ & $\begin{array}{l}3 \%) \\
4 \%) \\
3 \%)\end{array}$ & & \\
\hline
\end{tabular}

NA=Not Applicable

Table (5) Patient perception about care received from General Practitioner (GP) (n=72)

\begin{tabular}{lcccccc}
\multicolumn{1}{c}{ Variables } & \multicolumn{5}{c}{ Patients' response (\%) } \\
\cline { 2 - 7 } & Never & Rarely & Sometimes & Mostly & Always & NA \\
\hline $\begin{array}{l}\text { Agreement with GP about } \\
\text { needed care }\end{array}$ & $0(0.0)$ & $8(11.1)$ & $21(29.2)$ & $20(27.8)$ & $22(36.6)$ & $1(1.4)$ \\
\hline $\begin{array}{l}\text { GP communicating with } \\
\text { other providers }\end{array}$ & $0(0.0)$ & $17(23.6)$ & $15(20.8)$ & $17(23.6)$ & $16(22.2)$ & $7(9.7)$ \\
\hline $\begin{array}{l}\text { GP involving patient when } \\
\text { making decisions about } \\
\text { needed care }\end{array}$ & $2(2.8)$ & $16(22.2)$ & $24(33.3)$ & $14(19.4)$ & $12(16.7)$ & $4(5.6)$ \\
\hline $\begin{array}{l}\text { GP talking with patient } \\
\text { about future care }\end{array}$ & $2(2.8)$ & $10(13.9)$ & $9(12.5)$ & $15(20.8)$ & $15(20.8)$ & $21(29.2)$ \\
\hline
\end{tabular}

about future care

treatment of HTN puts economic pressure on the Egyptian economy. Drug cost is the major determinant of the cost of care. In Egypt, the drug cost of HTN (total antihypertensive market) during the year 2011 was more than one billion Egyptian pounds, a dramatic increase from 600 million in 2007.

Our study also highlighted that the patients who initiated therapeutic lifestyle were only $5.6 \%$ of the studied population, which considered very low rate of lifestyle modification or low counseling. It was considered as a deficient indicator for assessment of quality of care provided to hypertensive patients. Which is in agreement with study done by Asch et al. ${ }^{36}$ in USA as only $3.7 \%$ of their patients initiated therapeutic lifestyle modification.

Approximately $60 \%$ of our patients had uncontrolled HTN. This high rate is similar to the findings of several Arab studies, where almost two- thirds of the 
Table (6) Unpaid caregivers helping the studied patients with daily life $(n=72)$

\begin{tabular}{lrr}
\hline \multirow{2}{*}{\multicolumn{1}{c}{ Variables }} & \multicolumn{2}{c}{$\begin{array}{c}\text { Studied patients } \\
(\mathbf{n}=\mathbf{7 2})\end{array}$} \\
\cline { 2 - 3 } & No. & \% \\
\hline Unpaid caregivers & & \\
Spouse & 24 & 33.3 \\
Daughters & 14 & 19.4 \\
Sons & 12 & 16.7 \\
Parents & 2 & 2.8 \\
Other relatives & 2 & 2.8 \\
Others & 1 & 1.4 \\
\hline No caregivers & 17 & 23.6 \\
\hline Total & 72 & 100.0 \\
\hline
\end{tabular}

patients had uncontrolled HTN. The rates varied from $56 \%$ in Tunisia, $62.5 \%$ in Egypt to $79.8 \%$ in Syria. ${ }^{24,29,38}$ Asch et al. $^{36}$ found that poor control of BP was found in $58 \%$ of the studied patients. In the same manner study done at PHC centers in Saudi Arabia at 2001 revealed that $60 \%$ of hypertensive patients followed in PHC centers have uncontrolled SBP and 50\% have uncontrolled DBP. ${ }^{39}$ A similar pattern was shown in another study in Saudi Arabia, where uncontrolled BP was $63 \%$ in males and $76 \%$ in females. A lower figure $(28.8 \%)$ was reported by AlShammari et. al. ${ }^{40}$

Table (7) Patient perception about caregiver involvment in the received care $(n=72)$

\begin{tabular}{lccccc}
\hline \multirow{2}{*}{ Variables } & \multicolumn{5}{c}{ Patients' response (\%) } \\
\cline { 2 - 6 } & Never & Rarely & Sometimes & Mostly & Always \\
\hline $\begin{array}{l}\text { Caregiverinvolvment in } \\
\text { decision making of } \\
\text { received care }\end{array}$ & $0(0.0)$ & $12(16.7)$ & $23(31.9)$ & $14(19.4)$ & $23(31.9)$ \\
$\begin{array}{l}\text { Caregiver satisfaction } \\
\text { with received care }\end{array}$ & $1(1.4)$ & $6(8.3)$ & $16(22.2)$ & $13(18.1)$ & $36(50.0)$ \\
\hline
\end{tabular}

Table (9) Multivariate regression analysis model of factors affecting care performance among the studied patients $(n=72)$

\begin{tabular}{|c|c|c|c|c|}
\hline \multirow{2}{*}{ 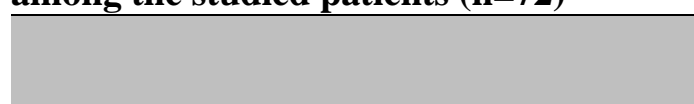 } & \multicolumn{2}{|c|}{ Coefficients } & \multirow{2}{*}{$\mathbf{T}$} & \multirow{2}{*}{ p-value } \\
\hline & B & Beta & & \\
\hline (Constant) & .711 & & .763 & .448 \\
\hline Age & .003 & .046 & .373 & .711 \\
\hline Gender & .245 & .156 & .841 & .404 \\
\hline Marital status & -.073 & -.062 & -.529 & .599 \\
\hline Occupation & .050 & .078 & .462 & .646 \\
\hline Educational level & .002 & .003 & .023 & .982 \\
\hline Smoking & -.449 & -.107 & -.807 & .423 \\
\hline Insurance & .531 & .247 & 1.833 & $.042 *$ \\
\hline Family history of HTN & -.098 & -.094 & -.730 & .468 \\
\hline HTN stage & -.512 & -.440 & -3.972 & $.0001 * *$ \\
\hline Perception about the received care & -.209 & -.183 & -1.598 & .116 \\
\hline Perception about caregiverinvolvment & -.209 & -.199 & -1.722 & $.040 *$ \\
\hline Perception about care received from GP & .204 & .187 & 1.624 & .110 \\
\hline Adequate quality of care received & .258 & .259 & 2.204 & $.032 *$ \\
\hline
\end{tabular}

*Significant $p<0.05$, highly significant $p<0.01, H T N=H T N$, GP=General Practitioner.

The high prevalence of uncontrolled HTN is due in part to a lack of awareness: $32 \%$ of people with the disease do not know they have it. Almost two-thirds of Arab patients with detected HTN are unaware of their high BP, ranging from $62.5 \%$ in Egypt to $79.8 \%$ in
Syria. ${ }^{24-29}$ One potential explanation for uncontrolled HTN is suboptimal quality of care. Studies have shown that many patients are not receiving essential antihypertensive care. ${ }^{41}$

Our data stated that the prevalence of inadequate care of hypertensive patients 
was higher than adequate care (56.9\% versus $43.1 \%$, respectively), which was in agreement of Berlowitz et al. ${ }^{41}$, who found that $40 \%$ of diagnosed hypertensive patients had inadequate care of BP despite an average of more than six HTN-related visits per year. This is in disagreement of study done by Asch et al. ${ }^{36}$ in which $64 \%$ of their patients received adequate care the difference may be due to different methodology, different sample size or patient perspectives. ${ }^{41}$

Our findings emphasized that the most common problems facing the patients were waiting too long till receiving the services $(83.3 \%)$. Waiting and treatment time are usually regarded as important determinants of patient satisfaction and service quality. Reducing outpatient's waiting time is not only valuable for patients but also helpful to decrease the clinic workload. ${ }^{42-43}$

In this regard, Aeenparast et al. ${ }^{44}$ stated that over a half of the patients complained from prolonged waiting time before physician's entrance at the clinic. They indicated that combining physician's work time changing with patient's entry time changing would decrease waiting time by $71.40 \%$.

The patients were also confused about the roles of different service providers $(33.3 \%)$. This may be due to the ineffective communication between the patients and health care professionals.

Table (8) Indicators for assessment of quality of care provided to hypertensive patients for the last year $(n=72)$

\begin{tabular}{lr}
\hline \multicolumn{1}{c}{ Variables } & $\begin{array}{c}\text { Studied patients } \\
(\mathbf{n = 7 2})\end{array}$ \\
\cline { 2 - 2 } & No. (\%) \\
\hline 1-Screening BP & $72(100.0)$ \\
2-Diagnosing of HTN (at least 3 measurements on different days) & $71(98.6)$ \\
3-Taking initial history and performing physical examination & $53(73.6)$ \\
4-Discontinuing drugs that causes HTN & $55(76.4)$ \\
5-Performing initial laboratory tests & $48(66.7)$ \\
6-Documenting diagnosis of HTN in therecords & $72(100.0)$ \\
7-Counselling about life style modification & $4(5.6)$ \\
8-Receiving pharmacotherapy & $70(97.2)$ \\
9-Following-up at least once each year & $72(100.0)$ \\
10-Changing in dose or regimen of antihypertensive agents & $42(58.3)$ \\
\hline Total score of quality of care & $33(45.8)$ \\
Inadequate & $39(52.2)$ \\
Adequate & $6.8 \pm 0.88$ \\
Mean \pm SD & $6-9$ \\
Range &
\end{tabular}

$B P=$ Blood pressure, $H T N=H T N$. Adequate quality of care means $60 \%$ or more.

There is significant correlation between patient-physician communication and positive patient's satisfaction. Health providers must spend enough time communicating with the patients to define their exact role in health service. ${ }^{45}$ The most common complaints of our patients included that GP never or rarely involving patient when making decisions about their needed care $(25.0 \%)$. In the same way, studies by El-Dib et al. ${ }^{46}$, Villas-Boas et al. ${ }^{47}$ and Levit et al. ${ }^{48}$ indicated that there is a lack of patients' involvement in decision making.

Patients' participation in decision making in health care and treatment causes improved disease control, better physical functioning, enhanced patients' compliance with secondary preventive 
actions and improvement in patients' health. ${ }^{49,50}$

Emphasizing the importance of participation in decision making process motivates the service provider and the health care team to promote participation of patients in treatment decision making. These efforts include enhancement of patient access to multifaceted information providing systems and tools that help patients in decision making. ${ }^{51}$ With enhanced patient participation, and considering patients as equal partners in healthcare decision making patients are encouraged to actively participate in their own treatment process and follow their treatment plan and thus a better health maintenance service would be provided. $^{52}$

Our research showed that GP rarely communicating with other providers $(23.6 \%)$. Researchers have found associations between better nursephysician communication and collaboration and more positive patient outcomes, i.e., lower mortality, higher satisfaction, and lower readmission rates. ${ }^{46,53,54}$

Effective communication among health care providers is challenging due to a number of interrelated dynamics. First, health care is complex and unpredictable, with health care providers from a variety of disciplines involved in providing care at various times throughout the day, often dispersed over several locations, creating spatial gaps with limited opportunities for regular synchronous interaction. ${ }^{55}$ Second, care providers often have their own disciplinary view of what the patient needs, with each provider prioritizing the activities in which he or she acts independently. ${ }^{56}$ Third, differences in education and training among professions often result in different communication styles and methods that further complicate the scenario and render communications ineffective. Fourth, although teamwork and effective communication are crucial for safe patient care, the educational curricula for most health care professions focus primarily on individual technical skills, neglecting teamwork and communication skills. ${ }^{57}$

According to our analysis, the overall negative patient perception about the received care was $40.3 \%$. The reason for this can be workload on physician during the day at the PHCU, which led to the tiredness of the physicians and their assisted staff that make them to be care less with the patients and in turn increase the negative perception of the patients. The gap between patients' expectations and perception indicates the level of the service quality. Good quality of care is achieved when the services delivered by the health providers meets the patient's perceptions, needs and expectations. ${ }^{58,59}$ The study performed by Abedi et al. ${ }^{60}$ showed that there was a great gap between patients' perceptions and their expectations. The service quality gaps indicated that the health care providers failed to meet the expectations of their patients. The results of this analysis provide evidence that service provider gaps must be reduced.

The majority of our patients had caregiver which include mostly the spouse $(33.3 \%)$, daughters $(19.4 \%)$ or sons $(16.7 \%)$. Meanwhile, $23.6 \%$ of the studied patients didn't have any caregiver which could over burden the patients

Our findings emphasized that the prevalence of inadequate quality of care was $47.8 \%$. Consistent with our results, Asch et al. ${ }^{61}$ found that the patient overall negative quality score was $43 \%$ of patients received suboptimal quality of care (i.e., they didn't receive all recommended care for which they were eligible).

One of the significant factors affecting care performance among our studied patients was absence of health insurance. In the same direction, Nguyen and 
Knowles $^{62}$ found demand increases significantly with the expected benefits of health insurance as measured by proximity to and quality of care at tertiary hospital. In disagreement with these findings, Abuosi et al. ${ }^{63}$ detected that there was no significant difference in perceptions of quality between insured and uninsured patients. However, there was a significant difference between insured and uninsured patients in respect of financial access to care

Our research showed that caregivers wereinvolved in the decision making of the received care $(83.2 \%)$ and caregivers were satisfied with the received care $(50 \%)$.

The CCM in the care of chronic conditions, such as HTN, emphasizes the role of hypertensive patients as being their own principal decision maker and the importance of caregivers and community support in self-management. Patients are at the center of the care model, with health providers, caregivers, and community interacting in different ways to influence and support health decisions. ${ }^{64-65}$

Health care providers must recognize the collaborative partnership between the patient, care team and caregivers, each with their own expertise in managing that person's health and who share in the decision-making process. This collaborative partnership is important in supporting the patient's management proactively during planned encounters and reactively as needed to make changes and adjustments in the treatment plan to achieve optimal care. , $^{5,66}$

\section{Conclusion}

The most deficient indicator for assessment of quality of care provided to hypertensive patients was lifestyle modification as the patients who initiated therapeutic lifestyle were only $5.6 \%$ of the studied population, which considered very low rate, The most common problems facing the patients were waiting too long till receiving the services $83.3 \%$ The most common complaints of the patients included that GP never/rarely involving patient when making decisions about needed care $(25.0 \%)$ and GP rarely communicating with other providers $(23.6 \%)$.

Also, there are several limitations of this study. First, the study was conducted in the urban area omitting the rural areas. Second, the interview with illiterate patients lacks the accurate response rate. Third, medical records were undefined regarding accuracy and completeness. Fourth, paid papers access was limited. Last, Egyptian researches were unpublished.

We recommended the encouragement of the recording system to enhance the quality of care. The improvement of physician adherence to the standard guidelines may be accomplished by conducting more training supervision. Training the physicians on better counseling toward life style modification are also suggested. Other researches could be done to compare quality of care in hospital setting versus primary care setting. Further studies are needed to improve physician counseling regard life style modification.

Recommendations: Raising the awareness of disease nature and its complications by health education, Improve compliance of patients to treatment, life style modification and follow, encouraging recording system to enhance the quality of care.

\section{References}

1. World Health Organization. Causes of death 2008: data sources and methods. Geneva: WHO, 2011

2. Whelton PK, Carey RM, Aronow WS, et al. 2017. ACC/AHA/AAPA/ ABC/ACPM /AGS/APhA/ASH/ASPC/NMA/PCNA

Guideline for the Prevention, Detection, Evaluation, and Management of High Blood 
Pressure in Adults: A Report of the American College of Cardiology/American Heart Association Task Force on Clinical Practice Guidelines. J Am Coll Cardiol 2017 Nov 13

3. Khera R, Lu Y, Saxena A, Nasir K, Krumholz HM. The impact of 2017 ACC/AHA guidelines on the prevalence of hypertension and eligibility for antihypertensive therapy in the United States and China. bioRxiv. 2017: 218859. doi:10.1101/218859Google Scholar

4. Muntner P, Carey RM, Gidding S, et al. Potential US population impact of the 2017 ACC/AHA high blood pressure guideline. Circulation. 2018;137(2):109118.PubMedGoogle ScholarCrossref .

5. Bodenheimer $\mathrm{T}$, Lorig $\mathrm{K}$, Holman $\mathrm{H}$. Patient self-management of chronic disease in primary care. JAMA. 2002; 288:2469-75.

6. Epping-Jordan JE, Pruitt SD, Bengoa R. Improving the quality of health care for chronic conditions. Qual Saf Health Care. 2004; 13:299-305.

7. Bodenheimer T. Interventions to improve chronic illness care: evaluating their effectiveness. Dis Manag. 2003; 6:63-71.

8. Tsai AC, Morton SC, Mangione CM.A meta-analysis of interventions to improve care for chronic illnesses. Am J Manag Care. $2005 ; 11: 478-88$.

9. Wang A, Wolf M, Carlyle R. The North Carolina experience with the diabetes health disparities Collaborative. Comm J Qual Saf. 2004; 30:396-404.

10.Perry HM Jr, Davis BR, Price TR. Effect of treating isolated systolic hypertension on the risk of developing various types and subtypes of stroke: The Systolic Hypertension in the Elderly Program (SHEP). JAMA. 2000; 284(4):465-71.

11.Hyman DJ, Pavlik VN. Characteristics of Patients with Uncontrolled Hypertension in the United States. N Engl J Med. 2001; 345:479-86.

12. Asch SM, Kerr EA, Lapuerta P. A New Approach for Measuring Quality of Care for Women with Hypertension. Arch Intern Med. 2001; 161:1329-35.

13.Schempf A, Politzer R, Wulu J. Immunization Coverage of Vulnerable Children: A Comparison of Health Center and National Rates. Medical Care Research and Review. 2003; 60(1): 85-100.

14.Hicks L, O'Malley A, Lieu T.The Quality of Chronic Disease Care in U.S. Community Health Centers. Health Affairs. 2006; 25(6):1712-23.

15.Chobanian AV, Bakris GL, Black HR, Cushman WC, Green LA, Izzo JL. Seventh report of the Joint National Committee on Prevention, Detection, Evaluation, and Treatment of High Blood Pressure. Hypertension. 2003;42(6):1206-52.

16.A New Approach for Measuring quality of Care for Women with Hypertension. Arch Intern Med. 2001; 161(10):1329-1335.

17.McGuiness C, Sibthorpe B. Development and initial validation of a measure of coordination of health care. Int J Qual Health Care. 2003; 15(4):309-18.

18. Ahmed ME, El-Awad IB. Blood Pressure Control and target organ complications among hypertensive patients in southern Saudi Arabia. East Med Health J. 2001;(4/5)7: 689-69.

19.Franklin SS, Wong ND. Hypertension and cardiovascular disease: contributions of the Framingham Heart Study. Glob Heart. 2013; 8:49-57.

20.Sheppard JP, Fletcher K, McManus RJ, et al. Prevalence and costs of treating uncomplicated stage 1 hypertension in primary care: a cross-sectional analysis. Br J Gen Pract. 2014 Oct 1;64(627): e641-8.

21.Gebreselassie KZ, Padyab M. Epidemiology of hypertension stages in two countries in sub-Sahara Africa: Factors associated with hypertension stages. Int $\mathbf{J}$ Hypertens. 2015; 2015:1-12.

22. Melo EM, Ferreira PL, Lima RA, et al. The involvement of parents in the healthcare provided to hospitalized children. Rev Latin Am Enferm. 2014;22(3):432-9.

23. Report on the regional consultation on hypertension prevention and control, Abu Dhabi, United Arab Emirates. Cairo, Egypt, World Health Organization, Regional Office for the Eastern Mediterranean, WHO-EM/ NCD/042/E; 2004.

24.Tazi MA, Abir-Khalil S, Chaouki N, et al. Prevalence of the main cardiovascular risk factors in Morocco: results of a National Survey. J Hypertens. 2003; 21:897-903. 
25.Bener A, Al-Suwaidi J, Al-Jaber K, AlMarri S, Elbagi I. Epidemiology of hypertension and its associated risk factors in the Qatari population. J Hum Hypertens. 2004; 18:529-530.

26. Al-Nozha MM, Abdullah M, Arafah MR, et al. Hypertension in Saudi Arabia. Saudi Med J. 2007; 28:77-84

27.Temmar M, Labat C, Benkhedda S, et al. Prevalence and determinants of hypertension in the Algerian Sahara. J Hypertens. 2007; 25:2218-2226.

28.. Jaddou HY, Bateiha AM, Al-Khateeb MS, Ajlouni KM. Epidemiology and management of hypertension among Bedouins in northern Jordan. Saudi Med J. 2003; 24:472-476.

29.Ben Khedda S, Temmar M, Bendaoud N, et al. Prevalence of Hypertension in Algeria: Results from A National Survey. Algeria: Mustapha Hospital Medical School; 2005; 23.

30..Al Riyami AA, Afifi M. Clustering of cardiovascular risk factors among Omani adults. East Mediterr Health J. 2003; 9:893903.

31.Kearney PM, Whelton M, Reynolds K, Muntner P, Whelton PK, He J. Global burden of hypertension: analysis of worldwide data. Lancet. 2005; 365:217-223. 32. Addo J, Smeeth L, Leon DA. Hypertension in sub-Saharan Africa: a systematic review. Hypertension. 2007; 50:1012-1018.

33. Tailakh A, Evangelista LS, Mentes JC, Pike NA, Phillips LR, Morisky DE. Hypertension prevalence, awareness, and control in Arab countries: a systematic review. Nurs Health Sci. 2014 Mar 1;16(1):126-130.

34. Wolf-Maier K, Cooper RS, Banegas JR, et al. Hypertension prevalence and blood pressure levels in 6 European countries, Canada, and the United States. JAMA. 2003; 289:2363-2369.

35. Chobanian AV, Bakris GL, Black HR, et al. National Heart, Lung, and Blood Institute Joint National Committee on Prevention, Detection, Evaluation, and Treatment of High Blood Pressure. National High Blood Pressure Education Program Coordinating Committee the Seventh Report of the Joint National Committee on Prevention,
Detection, Evaluation, and Treatment of High Blood Pressure: the JNC 7 report. JAMA. 2003; 289(19):2560-72.

36. Asch SM, McGlynn EA, Hiatt L, Adams J, Hicks J, DeCristofaro A, Chen R, LaPuerta P, Kerr EA. Quality of care for hypertension in the United States. BMC Cardiovasc Dis. 2005 Dec;5(1):1.

37.Ibrahim MM. Problem of hypertension in Egypt. Egypt Heart J. 2013; 65(3):233-4.

38. Abolfotouh MA, Soliman LA, Abolfotouh SM, Raafat M. Knowledge and practice of PHC physicians toward the detection and management of hypertension and other CVD risk factors in Egypt. International journal of hypertension. 2011 Aug 11;2011.

39. Siddiqui S, Ogbeide DO, Karim A, AlKhalifa I. Hypertension control in a community health center at Riyadh, Saudi Arabia. Saudi Med J. 2001; 22(1):49-52.

40.Al-Shammari SA, Nass M, Al-Maatouq MA, Al-Quaiz JM. Family practice in Saudi Arabia: chronic morbidity and quality of care. Int J Qual Health Care. 1996; 8(4): 383387.

41.Berlowitz DR, Ash AS, Hickey EC. Inadequate management of blood pressure in a hypertensive population. N Engl J Med. 1998; 339:1957-63.

42.Chen BL, Li ED, Yamawuchi K, Kato K, Naganawa S, Miao WJ. Impact of adjustment measures on reducing outpatient waiting time in a community hospital: application of a computer simulation. Chin Med J (Engl). 2010;123(5):574-80.

43.Günal MM, Pidd M. Discrete event simulation for performance modelling in health care: a review of the literature. J Simul. 2010;4(1):42-51.

44.Aeenparast A, Tabibi SJ, Shahanaghi K, Aryanejhad MB. Reducing outpatient waiting time: a simulation modeling approach. Iran Red Cres Med J. 2013 Sep;15(9):865-869.

45.Dingley C, Daugherty K, Derieg MK, Persing R. Improving patient safety through provider communication strategy enhancements. In: Henriksen K, Battles JB, Keyes MA, et al. (eds.). Advances in Patient Safety: New Directions and Alternative Approaches (Vol. 3: Performance and 
Tools). Agency for Healthcare Research and Quality (US); 2008.

46.El Dib RP, Atallah AN, Andriolo RB. Mapping the Cochrane evidence for decision making in health care. J Eva Clin Prac. 2007; 13:689-692.

47.Villas Boas PJ, Spagnuolo RS, Kamegasawa A, Braz LG, Polachini do Valle A, Jorge EC, Yoo HH, Cataneo AJ, Correa I, Fukushima FB, do Nascimento P, Modolo NS, Teixeira MS, de Oliveira Vidal EI, Daher SR, El Dib R. Systematic reviews showed insufficient evidence for clinical practice in 2004: What about in 2011? The next appeal for the evidence-based medicine age. J EvaluatClinPrac. 2012; 19(4):633637.

48.Levit L, Balogh E, Nass S, Ganz PA. Patient-centered communication and shared decision making. In: Levit L, Balogh E, Nass $\mathrm{S}$, et al. (eds.). Committee on Improving the Quality of Cancer Care: Addressing the Challenges of an Aging Population; Board on Health Care Services; Institute of Medicine; Washington (DC): National Academies Press (US); 2013; 12:27.

49. Arnetz JE, Almin I, Bergström K, Franzen Y, Nilsson H. Active patient involvement in the establishment of physical therapy goals: Effects on treatment outcome and quality of care. Adv Physiother. 2004; 6(2):50-69.

50.Loh A, Leonhart R, Wills CE, Simon D, Harter M. The impact of patient participation on adherence and clinical outcome in primary care. Patient Educ Couns. 2007;65(1):69-78

51.Vahdat S, Hamzehgardeshi L, Hessam S, Hamzehgardeshi Z. Patient involvement in health care decision making: a review. Iran Red Cres Med J. 2014; 16(1): e12454.

52.Kreindler SA. Patient involvement and the politics of methodology. Canadian Public Administration. 2009 Mar 1;52(1):113-24.

53.Baggs JG, Ryan SA, Phelps CE, et al. The association between interdisciplinary collaboration and patient outcomes in a medical intensive care unit. Heart Lung 1992; 21: 18-24.

54.Baggs JG, Schmitt MH, Mushlin AI, et al. Association between nurse-physician collaboration and patient outcomes in three intensive care units. Crit Care Med 1999; 27: 1991-1998.

55.Fagin C. Collaboration between nurses and physician: No longer a choice. Acad Med 1997; 5: 295-303

56.Zwarenstein M, Reeves S. Working together but apart: Barriers and routes to nurse-physician collaboration. Comm J Qual Improv 2002; 28: 242-247.

57.Institute for Safe Medication Practices. Medication safety alert. Intimidation: Practitioners speak up about this unresolved problem (Part I). 2008; 2:6. 184-

58.Scisney-Matlock M, Bosworth HB, Giger $\mathrm{JN}$, et al. Strategies for implementing and sustaining therapeutic lifestyle changes as part of hypertension management in African Americans. Postgrad Med. 2009; 121:147159.

59. Carter BL, Bosworth HB, Green BB. The hypertension team: the role of the pharmacist, nurse, and teamwork in hypertension therapy. J ClinHypertens. 2012;14(1):51-65

60. Abedi G, Rostami F, Nadi A. Patient's Perception and Expectations of the Quality of Outpatient Services of Imam Khomeini Hospital in Sari City. Materia Socio Med. 2015 Jul 1;27(4):272.

61.Caha H. Service quality in private hospitals in Turkey. J Econ Soc Res. 2007; 9:55-59.

62.Asch SM, Kerr EA, Lapuerta P, Law A, McGlynn EA. A new approach for measuring quality of care for women with hypertension. Arch Inter Med. 2001 May 28; 161(10):1329-35.

63.Isaacs A, Manga N, Le Grange C, Hellenberg DA, Titus V, Sayed R. Quality of care and cost of prescriptions for diabetes and hypertension at primary healthcare facilities in the Cape Town Metropole. South African Fam Prac. 2015;57(3):187-93.

64. Abuosi AA, Domfeh KA, Abor JY, Nketiah-Amponsah E. Health insurance and quality of care: Comparing perceptions of quality between insured and uninsured patients in Ghana's hospitals. Int J Equity Health. 2016 Dec;15(1):76.

65. Nguyen H, Knowles J. Demand for voluntary health insurance in developing countries: the case of Vietnam's school-age children and adolescent student health 
insurance program. Soci Sci Med. 2010 Dec 1;71(12):2074-82.

66. Oliveria SA, Lapuerta P, McCarthy BD, L'Italien GJ, Berlowitz DR, Asch SM. Physician-related barriers to the effective 67.
67. management of uncontrolled hypertension. Arch Intern Med. 2002;162(4):413-20. 